FISCHER SZ; BARBIERI RL; PEIL RMN; ERT STUMPF; NEITZKE RS; VASCONCELOS CS; TREPTOW RO. 2015. Abóboras ornamentais: atributos valorizados por consumidores finais e decoradores florais. Horticultura Brasileira 33:480-487. DOI - http://dx.doi.org/10.1590/S0102-053620150000400012

\title{
Abóboras ornamentais: atributos valorizados por consumidores finais e decoradores florais
}

\author{
Síntia Z Fischer ${ }^{1}$; Rosa L Barbieri²; Roberta MN Peil ${ }^{3}$; Elizabeth RT Stumpf ${ }^{1}$; Raquel S Neitzke ${ }^{4}$; Carla S \\ Vasconcelos $^{3}$; Rosa O Treptow ${ }^{2}$ \\ 'Instituto Federal de Educação Ciência e Tecnologia Sul-rio-grandense, Pelotas-RS, Brasil; sintiafischer@gmail.com; elisabethstumpf@

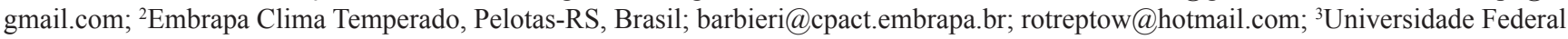 \\ de Pelotas (UFPel), Pelotas-RS, Brasil; rmpeil@ufpel.edu.br; carla_sigales@hotmail.com; ${ }^{4}$ Prefeitura Municipal de Arroio do Padre, Ar- \\ roio do Padre-RS, Brasil; raquelsilviana@gmail.com
}

\section{RESUMO}

No Rio Grande do Sul, agricultores familiares cultivam variedades crioulas de abóboras que apresentam potencial para uso ornamental, pela ampla variabilidade genética para características morfológicas. Algumas dessas variedades vêm sendo conservadas no Banco Ativo de Germoplasma de Cucurbitáceas da Embrapa Clima Temperado. Para colocar em uso esse germoplasma é essencial que ele seja caracterizado morfologicamente. Além da caracterização, informações sobre as preferências e a aceitação do mercado consumidor podem ser úteis. Desta forma, este trabalho teve como objetivo verificar a aceitação de abóboras ornamentais junto ao mercado consumidor (consumidor final e decoradores florais) e sua percepção com relação aos atributos ornamentais. Para tanto, foi realizada entrevista com consumidores finais e decoradores florais, através das quais eles indicavam os atributos ornamentais preferidos e o grau de satisfação, utilizando uma escala hedônica. Os atributos morfológicos de fruto selecionados foram formato, cor, textura e desenho produzido na casca pela cor secundária. Para verificar a aceitação dos frutos foi utilizada a escala de atitute (Food Action Rating Scale, FACT). Os resultados foram apresentados em porcentagem e representados por histogramas. Foram entrevistados 150 consumidores finais e 30 decoradores florais. Não foi evidenciada diferença expressiva entre consumidores finais e decoradores florais na preferência dos atributos estéticos das abóboras ornamentais. Os frutos das abóboras ornamentais apresentaram grande potencial de uso e valor ornamental, com excelente aceitação pelos consumidores, com valores hedônicos com média em torno de oito (dependendo do atributo).

Palavras-chave: Cucurbita, preferência, aceitação, decoração, floricultura.

\begin{abstract}
Ornamental pumpkins: traits valued by consumers and floral designers

Family farmers in Rio Grande do Sul State grow landraces of pumpkins that have potential for ornamental use due their wide genetic variability for morphological characteristics. Some of these landraces are conserved in the Cucurbitaceae Active Germplasm Bank of Embrapa Temperate Agriculture. To use this germplasm it is important to characterize it morphologically. Preferences and acceptance of the consumer market can be other useful information. So, this study aimed to verify the acceptance of ornamental pumpkins by the consumer market (consumers and floral designers) and their perception related to ornamental attributes. Therefore, consumers and floral designers were interviewed. They indicated which ornamental traits were preferred and the grade of satisfaction, using an hedonic scale. The morphological fruit traits selected were fruit shape, predominant skin color, skin texture and design formed by the secondary color in the skin. The scale action (Food Action Rating Scale, FACT) is used to verify the acceptance of the fruits. The results were presented as percentages and histograms. A total of 150 consumers and 30 floral designers were interviewed. No significant difference was observed between consumers and floral designers in the perception of aesthetic traits of ornamental pumpkins. The fruits of ornamental pumpkins have great potential for ornamental use and value, with excellent acceptance by consumers with hedonic value around eight.
\end{abstract}

Keywords: Cucurbita, preference, acceptance, decoration, floriculture.

(Recebido para publicação em 9 de junho de 2014; aceito em 24 de abril de 2015)

(Received on June 9, 2014; accepted on April 24, 2015)

$\mathrm{O}$ mercado da floricultura é dinâmico e marcado pela constante apresentação de novidades, como forma de atender às exigências do consumidor e de fomentar a atividade. Assim, é constante o lançamento de novas cul- tivares (por exemplo, rosas com cores diferenciadas ou maior durabilidade pós-colheita), a reinserção de espécies que caíram em desuso com o tempo (como samambaias e camélia, por exemplo) e a inovação com o uso de plantas que possuem outras aplicações que não ornamentais (como abacaxis, bananas, flores de pessegueiros, flores de cenoura e pimentas ornamentais) (Santos-Serejo et al., 2007; Souza et al., 2007; Fischer et al., 2009; Romano et al., 2009; Neitzke 
et al., 2010).

Neste sentido, os frutos de abóboras, Cucurbita spp., podem ser uma alternativa para uso na ornamentação, por apresentarem atributos que conferem valor estético pela ampla variabilidade genética para características morfológicas externas, como formato, cor, desenho produzido na casca, cor secundária, textura e firmeza da casca. Além disso, apresentam grande durabilidade pós-colheita, sendo que algumas variedades podem alcançar até um ano ou mais, mantendo suas características estéticas (Neitzke et al., 2007).

As abóboras apresentam grande importância para a agricultura familiar no Brasil e fazem parte da alimentação em várias regiões (Ramos \& Queiroz, 2005). No entanto, no que se refere ao uso ornamental, não existe um mercado estruturado. A comercialização ocorre esporadicamente em feiras livres de produtos hortifrutigranjeiros e, muito raramente, em floriculturas.

No Rio Grande do Sul, existem variedades crioulas de abóboras ornamentais que são cultivadas por agricultores familiares, as quais geralmente não são comercializadas, sendo cultivadas apenas para uso da própria família. Muitas destas variedades foram resgatadas e fazem parte do acervo do Banco Ativo de Germoplasma de Cucurbitáceas da Embrapa Clima Temperado (Barbieri et al., 2006). Estas variedades crioulas apresentam uma ampla diversidade morfológica para frutos com relação a tamanho, formato, cor e textura da casca. Esta diversidade poderia ser explorada com sucesso em diferentes tipos de decoração.

$\mathrm{Na}$ Europa, onde as abóboras foram introduzidas no século 16, provenientes das Américas (Paris et al., 2006), o uso ornamental está bem difundido. Fuchs (2001) relata uma das primeiras citações do uso de abóboras neste continente, em 1543, sendo que as abóboras de diversos tipos, inclusive ornamentais, já eram utilizadas em vários desenhos e pinturas da época (Janick \& Paris, 2006; Paris et al., 2006, 2009). Atualmente, os frutos de abóboras são utilizados para os mais variados fins, seja para as decorações de casas na época de outono, bem como complemento em arranjos florais (Hillier, 1996, 2001). Existe um mercado bem consolidado composto por várias empresas de sementes, inclusive fazendo parte do catálogo de produtos mais solicitados, organizado pelo Conselho de Flores da Holanda (Flower Council of Holland, 2009).

O mercado de abóboras ornamentais é um nicho que poderia ser melhor explorado no Brasil. Atualmente, as abóboras ornamentais encontradas no mercado nacional são oriundas de sementes importadas, implicando em custos de importação e pagamento de royalties (Heiden et al., 2007). Sendo assim, a valorização de variedades crioulas de abóboras ornamentais, através do cultivo em escala comercial, poderia se apresentar como uma alternativa de renda às propriedades de agricultura familiar. Para tanto, é essencial conhecer o germoplasma mantido nos bancos, através de caracterização morfológica, dispondo-o de uma forma mais efetiva para a utilização em programas de melhoramento (Ramos et al., 2009). O conhecimento do mercado consumidor, como por exemplo, os tipos e as cores preferidas, e a aceitação das abóboras ornamentais, pode ser outra informação útil para direcionar os trabalhos de melhoramento.

Segundo Matsuura et al. (2004), a pesquisa voltada para atributos de qualidade que definem a compra ou não de determinado produto pelo consumidor, pode aumentar as chances de sucesso de longo prazo, dos programas de melhoramento. Desta forma, os testes afetivos são uma importante ferramenta, pois acessam diretamente a opinião do consumidor já estabelecido ou potencial de um produto acerca de características específicas ou ideias do mesmo, por isso também chamado teste do consumidor (Ferreira et al., 2000). O teste afetivo é muito utilizado devido à confiabilidade e validade de seus resultados, além de fácil empregabilidade (Stone \& Sidel, 1993). É um método subjetivo e sensorial, que permite avaliar a opinião do consumidor através da preferência e/ou aceitação de um produto (Queiroz \& Treptow, 2006).

Assim, este trabalho teve como objetivo verificar a aceitação de abóboras ornamentais junto ao mercado consumidor (consumidor final e decoradores florais) e sua percepção com relação aos atributos ornamentais, bem como identificar o perfil dos consumidores entrevistados.

\section{MATERIAL E MÉTODOS}

Para verificar a aceitação das abóboras ornamentais junto ao mercado, consumidores finais e decoradores florais, e a percepção destes com relação aos atributos ornamentais, foram realizadas entrevistas individuais estruturadas, com perguntas pré-elaboradas e sistematicamente aplicadas aos entrevistados.

Para a avaliação, foram utilizados frutos de variedades crioulas de abóboras ornamentais das espécies $C$. maxima e C. pepo, integrantes do acervo do Banco Ativo de Germoplasma de Cucurbitáceas da Embrapa Clima Temperado. As plantas foram cultivadas em campo experimental e os frutos colhidos em março de 2010. A escolha dos frutos para serem utilizados na entrevista (Figura 1) foi realizada com base nos seguintes atributos ornamentais: formato do fruto (com presença de gomos, globular, cordiforme, discoide, periforme, cilíndrico, achatado, turbante superior, com pescoço curvo, com pescoço reto ou oval), cor (branco, verde claro e escuro, amarelo, laranja, laranja escuro, creme, marrom, salmão ou cinza), desenho produzido na casca pela cor secundária (sem cor secundária, pontilhado, manchado, listrado, estriado ou biseccional) e textura da casca (lisa, levemente enrugada, granulada ou com verrugas).

Foi utilizado um fruto como amostra de cada característica, sendo cada amostra codificada com números aleatórios de três dígitos, de acordo com a metodologia de Queiroz \& Treptow (2006), e exposta aos entrevistados em bandejas para avaliação. Cada bandeja continha um conjunto com as amostras de cada atributo a ser avaliado (formato, cor, desenho e textura).

Os consumidores foram caracterizados em dois grupos, o consumidor final (público de diversas categorias socioeconômicas e faixa etária) que compra elementos decorativos para seu uso pessoal e os decoradores florais (setor de serviços) que consomem para 
atender as necessidades de seus clientes. Essa caracterização foi feita a fim de estimar possíveis diferenças na percepção estética, uma vez que, possivelmente, o decorador tenha um olhar diferenciado por ter um conhecimento já adquirido pelo trabalho com plantas ornamentais. Foram entrevistados 180 consumidores, sendo 150 consumidores finais e 30 decoradores florais.

As avaliações por parte do consumidor final ocorreram em uma feira livre de produtos hortifrutigranjeiros e na Feira Nacional do Doce (FENADOCE) em Pelotas, no Rio Grande do Sul. Para a avaliação, as bandejas contendo as amostras ficaram expostas sobre bancadas, e as pessoas eram entrevistadas quando demonstravam interesse pelos frutos de abóbora ornamental. As avaliações junto aos decoradores florais foram realizadas em visitas aos respectivos locais de trabalho. Os decoradores florais foram localizados através de busca em sites na internet e listas telefônicas. As entrevistas, tanto de consumidores finais quanto de decoradores florais, foram conduzidas nos meses de maio e junho de 2010. O questionário aplicado foi dividido em três partes, constando de dados de identificação, dados de consumo e dados de preferência em relação aos atributos estéticos e de aceitação das abóboras crioulas ornamentais.

Os dados de identificação foram utilizados para apurar o perfil dos entrevistados. Para o consumidor final foi registrado o sexo, a faixa etária, a escolaridade, a profissão, a faixa de renda pessoal e a etnia. Para os decoradores florais foi excluído o item faixa de renda pessoal.

Nos dados de consumo, para o consumidor final, foi verificado o conhecimento prévio das abóboras ornamentais, sendo perguntado sobre o consumo regular de plantas ornamentais, se já conhecia as abóboras ornamentais, se comprasse as abóboras ornamentais em que ambiente da casa colocaria e qual o atributo estético das abóboras ornamentais que considera mais interessante para a ornamentação. No caso dos decoradores florais, foi questionado sobre o conhecimento das abóboras ornamentais, se costuma utilizar em decorações, como usaria em decorações e também sobre qual atributo estético considera mais interessante para decoração.

Nos dados de preferência, foi apurada a percepção dos entrevistados, consumidor final e decorador floral, quanto aos principais atributos estéticos das abóboras ornamentais, como textura da casca, desenho produzido na casca pela cor secundária, cor da casca e formato do fruto. Foi solicitado aos entrevistados que indicasse qual era a amostra de abóbora ornamental preferida, em cada um dos atributos. Para expressar o quanto gostou ou desgostou de cada atributo apresentado foi utilizada uma escala hedônica estruturada de nove pontos.

Os valores da escala, variando de 9 a 1, incluem as opções gostei muitíssimo, gostei muito, gostei moderadamente, gostei ligeiramente, indiferente, desgostei ligeiramente, desgostei moderadamente, desgostei muito e desgostei muitíssimo. Para os atributos cor da casca, desenho produzido na casca pela cor secundária e textura da casca, os entrevistados podiam escolher apenas uma amostra. Para o atributo formato do fruto os entrevistados deviam ordenar as três amostras que mais lhe chamaram a atenção. Ainda nos dados de preferência, foi verificada a escala de atitute (Food Action Rating Scale, FACT), que permite conhecer a intenção de compra de determinado produto e, desta forma, sua aceitação. Esta escala foi modificada a partir da escala hedônica, sendo empregados cinco pontos, com as opções certamente compraria, possivelmente compraria, talvez comprasse, possivelmente não compraria e certamente não compraria, de acordo com a metodologia de Queiroz \& Treptow (2006).

Os resultados foram apresentados em porcentagem, obtidos a partir da análise de tabelas de frequência simples, em relação ao número total de pessoas consultadas, em cada tipo de entrevistado (consumidor final e decorador floral). A partir destes resultados, para a análise de preferência e aceitação, foram elaborados histogramas da porcentagem de respostas para cada característica avaliada e da atitude de compra por parte dos consumidores. Os histogramas possibilitam a visualização da segmentação dos valores hedônicos de cada amostra, revelando o nível de aceitação e rejeição da mesma e permitindo a comparação dos desempenhos de duas ou mais amostras que participaram da avaliação.

\section{RESULTADOS E DISCUSSÃO}

A figura 2 apresenta o perfil dos entrevistados. Dos consumidores finais entrevistados, $71 \%$ eram do sexo feminino, $42 \%$ estavam na faixa etária de 25-44 anos, 24\% possuía ensino médio completo, quanto à etnia, $30 \%$, se auto denominavam de etnia brasileira, sendo classificados na categoria outra, seguidos pela etnia alemã, italiana e portuguesa, com $20 \%$ cada uma. O nível de renda dos consumidores finais variou de sem salário (12\%), menos de um salário $(7 \%)$, de um a três salários (37\%), quatro a seis salários (19\%), sete a nove salários (12\%) e acima de 10 salários (13\%).

A grande maioria dos decoradores florais (93\%) era do sexo feminino, 41\% estavam na faixa etária de 45-54 anos, $27 \%$ tinham ensino médio completo, quanto à profissão $54 \%$ se denominava florista e $50 \%$ era de etnia alemã.

$\mathrm{O}$ fato de a maioria dos entrevistados ser do sexo feminino pode indicar que as mulheres possuem um olhar diferenciado na procura de elementos decorativos. É significativo destacar a influência da etnia sobre a apreciação das plantas ornamentais. Normalmente os europeus têm este olhar e procuram se cercar de elementos naturais na decoração, fato constatado por observação própria dos autores. A profissão de 75\% dos consumidores finais e de $54 \%$ dos decoradores florais entrevistados que se denominam floristas foi enquadrada no setor terciário, que é o setor de serviços.

$\mathrm{Na}$ avaliação dos dados, foi verificado que todas as faixas de idade, graus de escolaridade e níveis de renda foram contemplados na pesquisa. Durante as entrevistas, foi observado grande interesse dos entrevistados pelas abóboras ornamentais; as pessoas queriam inclusive comprar as amostras usadas na pesquisa.

Quando questionados a respeito da compra de plantas ornamentais, $49 \%$ dos consumidores finais afirmaram comprar plantas ornamentais ocasionalmente, $28 \%$ frequentemente e $23 \%$ indicaram 


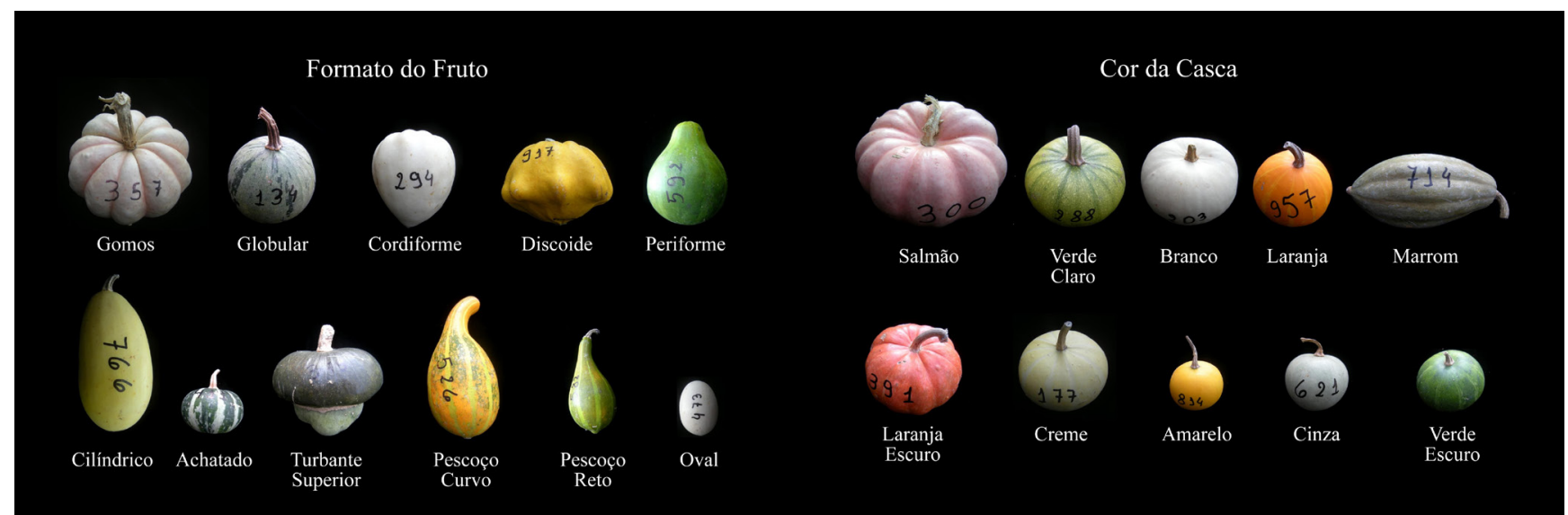

Desenho produzido na casca pela cor secundária

Textura da Casca

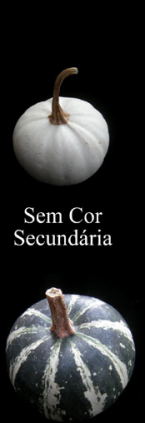

Listrado

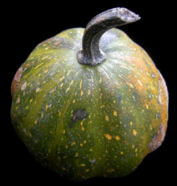

Pontilhado

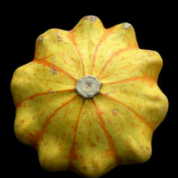

Estriado

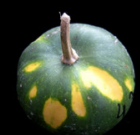

Manchado

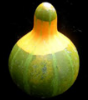

Biseccional

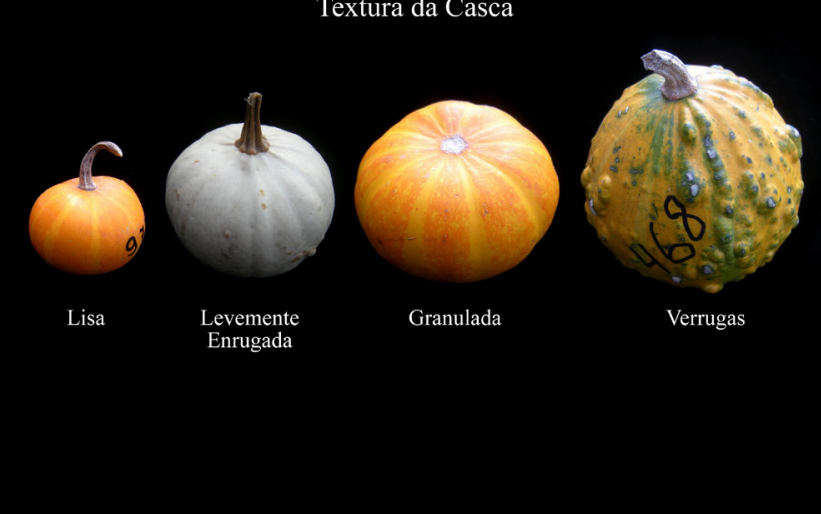

Figura 1. Formato, cor da casca, desenho produzido na casca pela cor secundária, textura da casca de frutos de abóboras ornamentais avaliados por consumidores finais e decoradores florais (shape, skin color, drawing produced in the skin by the secondary color and skin texture of ornamental pumpkins fruits evaluated by consumers and floral designers). Pelotas, UFPEL, 2012.

nunca comprar plantas ornamentais. Estes dados demonstram que, embora o consumo de plantas ornamentais possa ser considerado supérfluo para algumas pessoas, o consumo, entre os entrevistados, é bastante expressivo. Estes dados reforçam a afirmação de Silva (2012), que ressalta que o Rio Grande do Sul é o estado com maior média de consumo per capita de plantas ornamentais no Brasil, com uma média de 23,00 dólares/ano. De acordo com Junqueira \& Peetz (2012), o consumidor brasileiro de plantas ornamentais apresenta características de um mercado não totalmente maduro. Este fato se traduz em características como baixo índice de consumo per capita e número de compradores frequentes com compra centrada em produtos tradicionais e forte concentração sazonal de demanda em datas específicas (dia das mães, dos namorados, etc). Segundo estes autores, no país, o consumo médio per capita de flores e plantas ornamentais é de 8,00 dólares/ano, o que pode ser considerado bastante baixo quando comparado aos padrões internacionais de consumo, como 170,00 dólares/ano na Suíça. Porém, percebe-se uma alta capacidade de crescimento. Para Junqueira (2012), na contemporaneidade, o consumo em geral reflete aspectos relevantes das expressões identitárias pessoais e grupais e, assim, se reveste de significados narrativos sobre a percepção pessoal e de pertencimento ao mundo e à natureza. Esta afirmação pode ajudar a explicar o fato de o Rio Grande do Sul apresentar o maior consumo de plantas ornamentais no país, devido à sua colonização ter ocorrido predominantemente por imigrantes europeus. Os povos europeus têm uma relação de admiração pela natureza e, consequentemente, as plantas ornamentais são, por eles, especialmente valorizadas, característica essa que passa de geração a geração.
Com relação ao conhecimento de abóboras ornamentais, 54\% dos decoradores florais e dos consumidores finais afirmaram já conhecer as abóboras ornamentais. As pessoas que disseram conhecer as abóboras ornamentais ressaltaram que as conheceram através dos trabalhos de divulgação da Embrapa Clima Temperado, como entrevistas em programas de televisão e estandes em eventos. De fato, nos últimos anos, a Embrapa Clima Temperado tem divulgado a possibilidade de uso de abóboras ornamentais na decoração em diversos meios de comunicação, cujos vídeos estão disponíveis no Youtube (Terra Sul, 2010), além de publicações da série Embrapa (Barbieri et al., 2006; Heiden et al., 2007; Priori et al., 2010), trabalhos em congressos (Barbieri et al., 2005, 2007; Neitzke et al., 2007; Fischer et al., 2010) e artigos de jornal (Barbieri, 2004; Barbieri \& Stumpf, 2007).

$\mathrm{Na}$ avaliação com os decoradores 


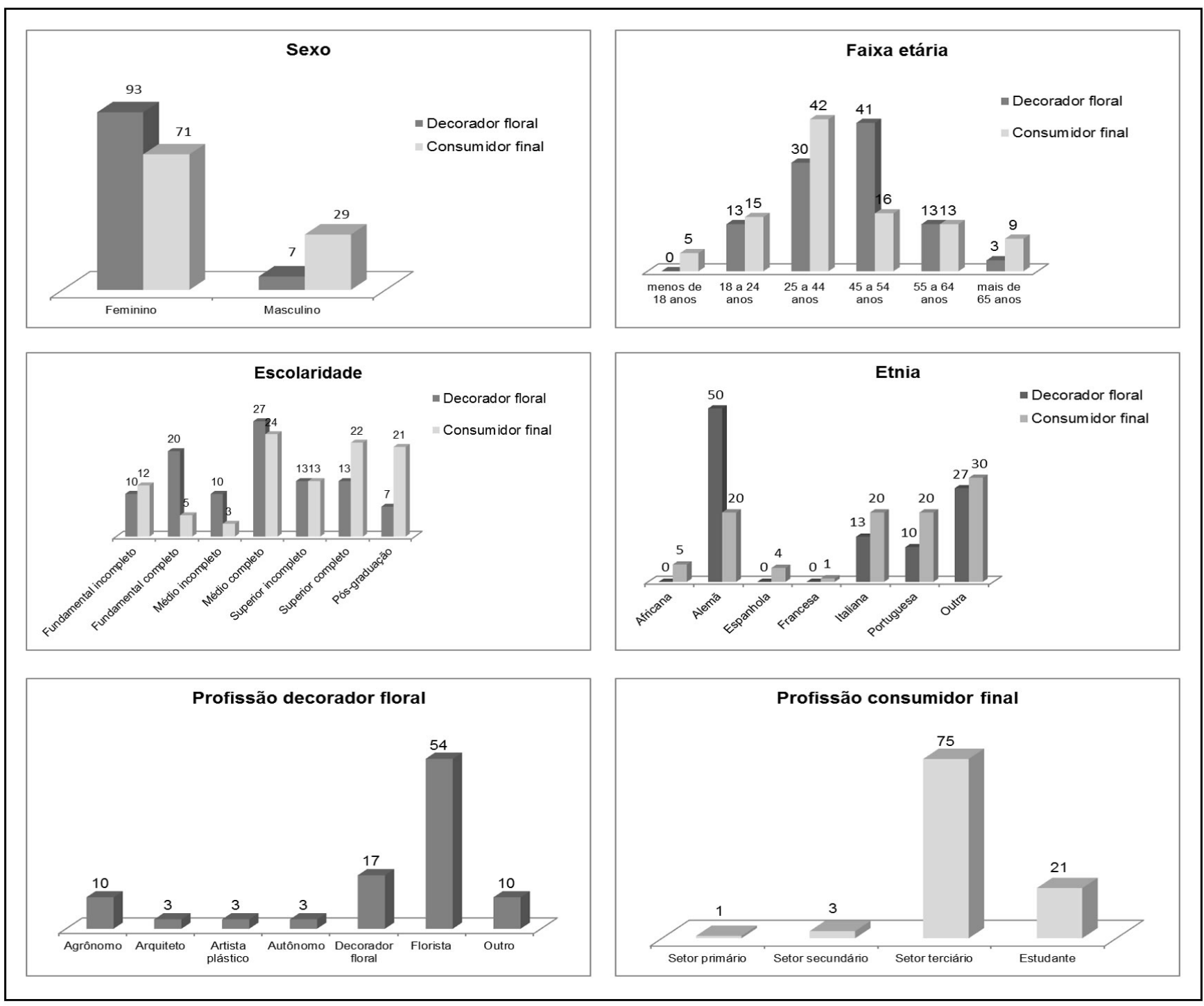

Figura 2. Histograma de frequências do perfil dos consumidores entrevistados quanto à aceitação e preferência dos atributos estéticos de abóboras ornamentais (histogram of frequencies with the profile of consumers interviewed to verify the acceptance and preference with respect to aesthetic traits of ornamental pumpkins). Pelotas, UFPEL, 2012.

florais acerca do uso de abóboras ornamentais, $77 \%$ afirmaram nunca ter comprado abóboras ornamentais para utilizar em suas decorações. Essa baixa adoção pode estar relacionada à pouca disponibilidade desses produtos no mercado, já que os decoradores florais compram os produtos para suas decorações em floriculturas ou fornecedores habituais (comerciantes que trazem os produtos em caminhões do estado de São Paulo), que dificilmente possuem frutos de abóboras ornamentais para ofertar. O consumidor final pode ter acesso aos frutos de abóboras ornamentais na feira municipal de hortifrutigranjeiros de Pelotas, pois um dos feirantes oferta os frutos na época de safra (dezembro-janeiro).

Quanto à forma de uso, $84 \%$ dos decoradores florais responderam que usariam com outros elementos, como plantas desidratadas, frutas e flores, utilizando cestas para montar composições. Para 70\% dos consumidores finais o melhor ambiente para as abóboras é na decoração da cozinha, e citaram também o uso de cestas e outros objetos de decoração. Foram entrevistadas ainda duas pessoas que usam as abóboras para decorar seus restaurantes. Segundo elas, as abóboras ornamentais são adquiridas sempre que encontradas no mercado, por apresentarem um diferencial, por serem incomuns, e o que chama mais atenção são os tamanhos, as cores e a durabilidade (mais de três meses, segundo a entrevistada). Estas entrevistadas mencionaram que um dos entraves é a sazonalidade da oferta, uma vez que gostariam de ter sempre estes frutos para a decoração do ambiente do restaurante, pois as abóboras chamam a atenção dos frequentadores que sempre elogiam e fazem perguntas sobre os frutos.

A respeito do atributo que considera mais relevante para utilizar na ornamentação, $60 \%$ dos decoradores florais responderam que o formato é o que chama mais atenção, seguido pela cor com $28 \%$ das respostas. Já para os consumidores finais a cor é mais atraente para $37 \%$, seguida do formato para $33 \%$ dos entrevistados. A textura é um 


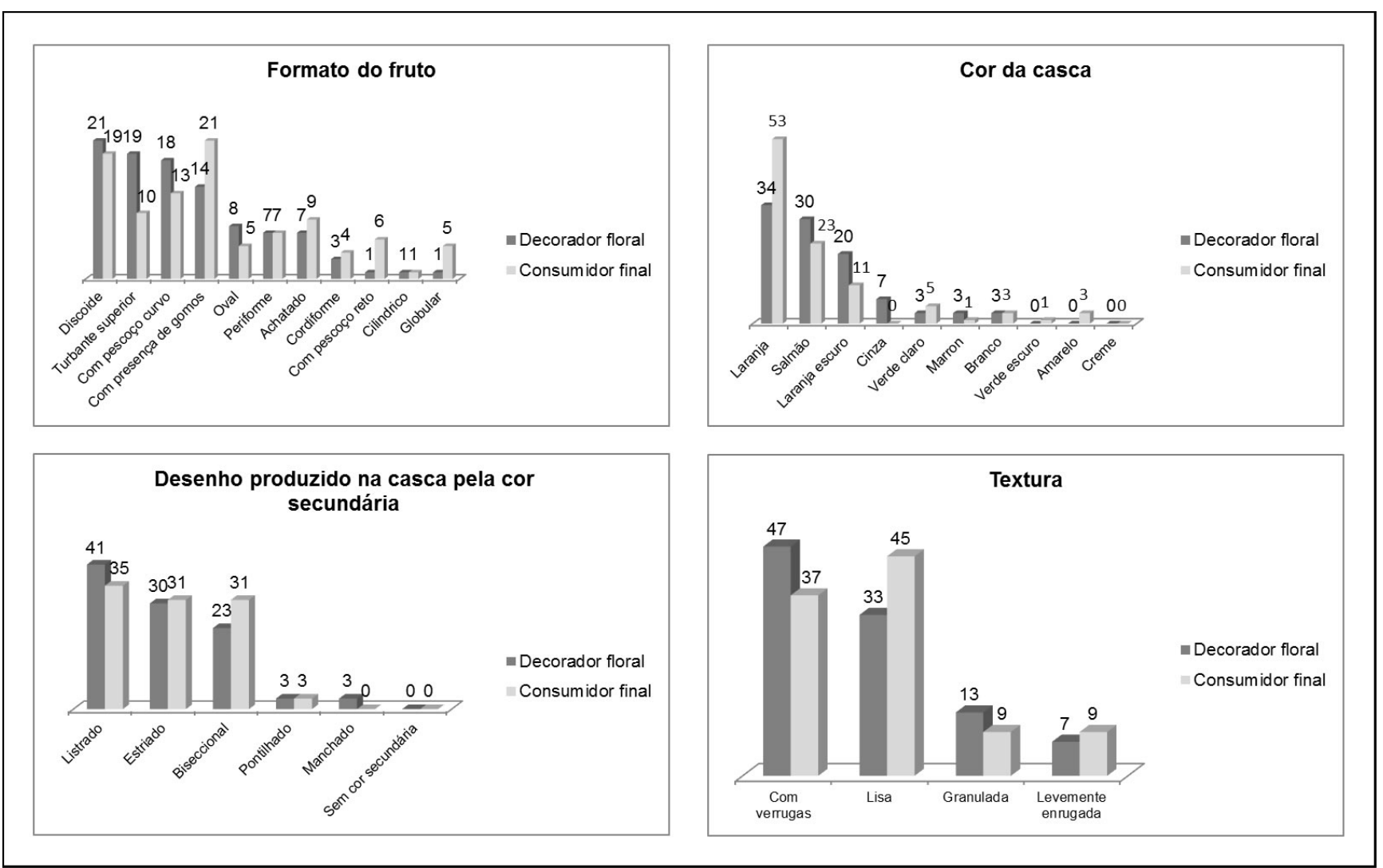

Figura 3. Histograma de frequências das preferências dos consumidores entrevistados quanto aos atributos estéticos de abóboras ornamentais (histogram of frequencies of consumers interviewed with respect to the preference to aesthetic traits of ornamental pumpkins). Pelotas, UFPEL, 2012.

atributo que parece não influenciar no valor ornamental, apenas $2 \%$ dos consumidores finais citaram esta característica e nenhum decorador floral a mencionou.

Deliza (2000) ressalta que a aparência é o atributo que mais causa impacto na escolha por parte do consumidor e, dentro desta, a cor é a característica mais relevante, em se tratando de hortifrutigranjeiros. Isto porque a cor caracteriza sobremaneira um produto, constituindo o primeiro critério para sua aceitação ou rejeição. Para a floricultura e a arte floral, os elementos utilizados, igualmente, devem apresentar características especiais como forma, cor, tamanho e textura (Scace, 2001), que determinam um aspecto visual agradável. Segundo Kikuchi (1995), as cores, formas e tamanhos motivam a preferência por determinados elementos que podem servir para ornamentação. Assim, os dados relativos a abóboras ornamentais levantados junto aos entrevistados demonstram que a opinião dos decoradores florais e consumidores finais está em consonância com os critérios ornamentais ressaltados por estes autores especializados em arte floral.

Para a arte floral, os atributos forma, cor e textura, são elementos essenciais para elaboração de composições (Kikuchi, 1995; Smith, 2006; Pryke, 2011). As respostas da preferência dos atributos das abóboras ornamentais dos consumidores finais e decoradores florais foram bastante semelhantes entre si (Figura 3), não havendo diferenças marcantes na percepção estética.

Os formatos preferidos foram discoide, turbante superior, com pescoço curvo e com presença de gomos, variando apenas a ordem de preferência entre os consumidores finais e os decoradores florais. A preferência dos decoradores florais no atributo formato ficou em $21 \%$ para o formato discoide, $19 \%$ para o formato turbante superior, $18 \%$ para o formato com pescoço curvo e $14 \%$ para formato com presença de gomos. Para o consumidor final, as preferências foram de $21 \%$ para o formato com presença de gomos, $19 \%$ para o formato discoide, $13 \%$ para o formato pescoço curvo e
$10 \%$ para o formato turbante superior. Provavelmente esses formatos foram escolhidos por serem os mais inusitados e, portanto, chamaram mais a atenção, principalmente para os decoradores florais, os quais estão sempre em busca de novidades para atender seus clientes. No caso dos consumidores finais, mesmo sem ter o conhecimento formal dos princípios da arte floral, demonstraram intuitivamente ter a mesma percepção. Conforme ressaltado por Hall (1993), Hillier (1996) e Krabbe (2010), o formato dos elementos é importante na composição de arranjos, pois pode dar ideia de movimento, transmitir suavidade (formas arredondadas) e/ou agressividade (formas pontiagudas).

A cor dos elementos (flores, folhagens e outros complementos) é um princípio de destaque para a arte floral, pois pode imprimir suavidade ou excitação, criar contrastes ou harmonia de cores (Hall, 1993). As cores preferidas por consumidores finais e decoradores florais foram, respectivamente, laranja (53\% e $34 \%)$, salmão $(23 \%$ e $30 \%)$ e 
laranja escuro (11\% e $20 \%$ ), as outras cores não foram significativas. Este resultado pode ter explicação pelo fato de o consumidor esperar uma determinada cor para cada produto e qualquer alteração nesta pode diminuir sua aceitabilidade (Deliza, 2000), sendo a cor laranja e seus matizes, a cor que as pessoas estão predispostas a esperar em frutos de abóbora. O tom alaranjado pode ser explorado favoravelmente em composições ornamentais, misturado com vários tons, segundo Pryke (2011), junto ao verde adquire um ar tropical, com roxo escuro se torna suntuoso e harmonioso, já em uma mistura multicor é quase psicodélico. $\mathrm{O}$ alaranjado remete ainda ao outono. Como no Hemisfério Norte a colheita de abóboras é realizada nesta estação do ano, elas são bastante utilizadas nas decorações outonais (Hillier, 1996, 2001; Krabbe, 2010; Pryke, 2011), além de transmitirem uma sensação de aconchego e rusticidade.

O desenho produzido na casca pela cor secundária dos frutos de abóboras ornamentais pode ser incluído no atributo cor dos elementos da arte floral. É uma característica extraordinária, pois pode-se criar movimento e contrastes nas composições. $\mathrm{O}$ desenho listrado foi o preferido por $35 \%$ dos consumidores finais e $41 \%$ dos decoradores florais, seguido pelo estriado (31\% e $30 \%)$ e pelo biseccional (31\% e 23\%). A preferência por amostras com os desenhos pontilhado, manchado e sem cor secundaria não foi expressiva.

Para o atributo textura, $45 \%$ dos consumidores finais preferiram a textura lisa, seguida de $37 \%$ de textura com verrugas. Já os decoradores preferiram a textura com verrugas, com $47 \%$ da preferência, seguida da lisa, com 33\%. A textura é um atributo de grande importância para a arte floral, embora para os entrevistados não seja uma característica que chame tanto a atenção, como citado anteriormente. Em composições ornamentais, a mescla de diferentes texturas é estimulante e transmite a ideia de contraste e movimento, enquanto que o uso de texturas semelhantes cria uma composição mais suave e delicada (Hall, 1993; Hillier, 1996).

Como o valor estético/ornamental é algo subjetivo e muito pessoal, a escala hedônica é muito útil, pois é um método subjetivo de avaliação que se refere aos estados conscientes, agradáveis ou desagradáveis, e visa justamente avaliar a aceitação/preferência do consumidor individualmente (Queiroz \& Treptow, 2006). Na escala hedônica, a categoria "nem gostei, nem desgostei" (valor 5) é considerada como uma região de indiferença da relação afetiva do avaliador com o produto, dividindo a escala em duas outras regiões: a região de aceitação (valores de 6 a 9), e a região de rejeição do produto (valores de 1 a 4). Os valores hedônicos encontrados neste trabalho ficaram com média em torno de 8 (dependendo do atributo). Em sua grande maioria, o valor da escala hedônica ficou acima de 7, apenas dois entrevistados deram nota 6 para o atributo textura. Estes valores indicam grande relação afetiva de aceitação das amostras de abóboras ornamentais por parte dos entrevistados.

Com relação à escala de atitute (Food Action Rating Scale, FACT), onde é possível verificar a intenção de compra, 49\% dos consumidores finais e $47 \%$ dos decoradores florais afirmaram que certamente comprariam as abóboras ornamentais se estas estivessem disponíveis para compra. Em menor proporção, 29\% e 33\% (consumidores finais e decoradores florais, respectivamente) possivelmente compraria, $17 \%$ e $10 \%$ talvez compraria, $3 \%$ e $10 \%$ possivelmente não compraria e, $2 \%$ e $0 \%$ não compraria. Esses dados são promissores no sentido de que demonstram o grande interesse em adquirir as abóboras ornamentais, tanto por parte dos decoradores florais quanto dos consumidores finais.

É importante salientar alguns comentários feitos pelos entrevistados. Vários disseram que era muito difícil escolher porque todas as amostras eram lindas, citaram a diversidade como um aspecto que chamou muito sua atenção. Os entrevistados apresentaram ainda grande interesse em cultivar as abóboras ornamentais, questionando acerca do cultivo e onde conseguir sementes.

Diante do exposto acima, pode-se concluir que a preferência dos atributos estéticos no que se refere a formatos de fruto é para discóide, turbante superior, com pescoço curvo e com presença de gomos. Para o atributo cor da casca do fruto a preferência é pela cor laranja e seus matizes e os desenhos produzidos na casca do fruto pela cor secundária preferidos são listrado e bisseccional. As texturas da casca do fruto preferidas são lisa e com verrugas. Estas informações podem apoiar decisões em programas de melhoramento genético de abóboras ornamentais, focando nestes atributos para futuras seleções em linhagens promissoras. Não há diferença entre consumidores finais e decoradores florais na percepção dos atributos estéticos das abóboras ornamentais. Os frutos das abóboras ornamentais apresentam grande potencial de uso e valor ornamental, com excelente aceitação pelos consumidores finais quanto decoradores florais.

\section{AGRADECIMENTOS}

Aos entrevistados pela disponibilidade, interesse e atenção demonstrados nas entrevistas. À CAPES (Coordenação de Aperfeiçoamento de Nível Superior) pela bolsa de doutorado cedida ao primeiro autor.

\section{REFERÊNCIAS}

BARBIERI RL. 2004, 14 novembro. Variedades crioulas de abóboras do Sul do Brasil: um patrimônio genético e cultural da agricultura familiar. Diário da Manhã. p. 13.

BARBIERI RL; HEIDEN G; NEITZKE RS; GARRASTAZÚ MC; SCHWENGBER JE. 2006. Banco ativo de germoplasma de Cucurbitáceas da Embrapa Clima Temperado - período de 2002-2006. Pelotas: Embrapa Clima Temperado. $21 \mathrm{p}$.

BARBIERI RL; HEIDEN G; NEITZKE RS; STUMPF ERT; FISCHER SZ. 2005. Utilizando abóboras como elementos de ornamentação. In: CONGRESSO BRASILEIRO DE FLORICULTURA E PLANTAS ORNAMENTAIS, 15. Revista da Associação Brasileira de Horticultura 23: p. 581-582.

BARBIERI RL; NEITZKE RS; HEIDEN G; FISCHER SZ; BUTOW MV. 2007. Diversidade morfológica em frutos de Cucurbita do banco ativo de germoplasma de Cucurbitáceas do Sul do Brasil. In: CONGRESO NACIONAL DE LA SOCIEDAD URUGUAYA DE HORTIFRUTICULTURA, 11 Y CONGRESO PANAMERICANO PROMOCIÓN DEL CONSUMO DE FRUTAS Y HORTALIZAS, 
3. Resumos... Montevideo: (CD-ROM).

BARBIERI RL; STUMPF ERT. 2007, 20 outubro. Abóboras ornamentais, por que não?. Diário da Manhã. p. 11

DELIZA R. 2000. Importância da qualidade sensorial em produtos minimamente processados. In: ENCONTRO NACIONAL SOBRE PROCESSAMENTO MÍNIMO DE FRUTAS E HORTALIÇAS, 2. Palestras... Viçosa: UFV. p. 73-74.

FERREIRA VLP; ALMEIDATCA; PETTINELLI MLCV; SILVA MAAP; CHAVES JBP; BARBOSA EMM. 2000. Análise sensorial: testes discriminativos e afetivos. Campinas: SBCTA, 127p.

FISCHER SZ; CASTRO CM; STUMPF ERT; BARBIERI RL; GROLLI PR. 2009. Produção de hastes florais de cenoura para uso na floricultura. Magistra 21: 337-342.

FISCHER SZ; NEITZKE RS; VASCONCELOS CS; BARBIERI RL; PEIL RMN; SCHWENGBER JE. 2010. Abóboras ornamentais no Banco ativo de germoplasma da Embrapa Clima Temperado. In: CONGRESSO BRASILEIRO DE RECURSOS GENÉTICOS. I. Resumos... Salvador: SBRG (CD-ROM).

FLOWER COUNCIL OF HOLLAND. 2009. Flower from Holland naturally. Leiden: Bloemenbureu Holland. 167p.

FUCHS L. 2001. The new herbal of 1543, New Kräuterbuch. Cologne: Taschen. 960p.

HALL J. 1993. Livro criativo de arranjos florais. São Paulo: Manole. 128p.

HEIDEN G; BARBIERI RL; NEITZKE RS. 2007. Chave para identificação das espécies de abóboras (Cucurbita, Cucurbitaceae) cultivadas no Brasil. Pelotas: Embrapa Clima Temperado. 31p.

HILLIER M. 1996. Arranjos de flores secas: guia para cultivo, secagem e apresentação. Londres: Dorling Kindersley. 160p.

HILLIER M. 2001. Blumen: kreative Arrangements für das ganze Jahr. München: Dorling Kindersley. 515p.

JANICK J; PARIS HS. 2006. The Cucurbit images (1515-1518) of the Villa Farnesina. Annals of Botany 97: 165-176.

JUNQUEIRA AH. 2012. Consumo de flores e plantas ornamentais: momento atual incentiva planejamento para o futuro. Disponível em: http://www.jornalentreposto.com.br/feirade-flores/flores/3492-consumo-de-florese-plantas-ornamentais-no-brasil-momentoatual-incentiva-planejamento-para-o-futuro/ Acessado em 13 de março de 2012.

JUNQUEIRA AH; PEETZ MS. 2012. A floricultura brasileira no contexto da crise mundial. Disponível em: http://www.hortica. com.br/artigos/A_floricultura_brasileira_no contexto_da_crise_financeira_mundial-1.pdf./ Acessado em 13 de março de 2012.

KIKUCHI OY. 1995. Ornamentação floral. São Paulo: Editora SENAC. 73p.

KRABBE W. 2010. Kränze \& Blumenschmuck. München: Bassermann Verlag. 124p.

MATSUURA FCAU; COSTA JIP; FOLEGATTI MIS. 2004. Marketing de banana: preferências do consumidor quanto aos atributos de qualidade dos frutos. Revista Brasileira de Fruticultura (on line) 26: 48-52.

NEITZKE RS; BARBIERI RL; RODRIGUES WF; CORREA IV; CARVALHO FIF. 2010. Dissimilaridade genética entre acessos de pimenta com potencial ornamental. Horticultura Brasileira 28: 47-53.

NEITZKE RS; BÜTTOW MV; HEIDEN G; OLIVEIRA C; FISCHER SZ; BARBIERI RL. 2007. Durabilidade pós-colheita de abóboras ornamentais. In: CONGRESO NACIONAL DE LA SOCIEDAD URUGUAYA DE HORTIFRUTICULTURA, 11 Y CONGRESO PANAMERICANO PROMOCIÓN DEL CONSUMO DE FRUTAS Y HORTALIZAS, 3. Resumos... Montevideo (CD-ROM).

PARIS HS; DAUNAY MC; JANICK J. 2009. The Cucurbitaceae and Solanaceae illustrated in medieval manuscripts known as the Tacuinum Sanitatis. Annals of Botany 103: 1187-1205.

PARIS HS; DAUNAY MC; PITRA M; JANICK J. 2006. First known image of Cucurbita in Europe, 1503-1508. Annals of Botany 98: 41-47.

PRIORI D; BARBIERI RL; NEITZKE RS; VASCONCELOS CS; OLIVEIRA CS; MISTURA CC; COSTA FA. 2010. Acervo do Banco Ativo de Germoplasma de Cucurbitáceas da Embrapa Clima Temperado - período de 2002-2010. Pelotas: Embrapa
Clima Temperado. $37 \mathrm{p}$.

PRYKE P. 2011. Desenho floral. Barcelona: Blume. 384p.

QUEIROZ MI; TREPTOW RO. 2006. Análise sensorial para a avaliação da qualidade dos alimentos. Rio Grande: FURG. 268p.

RAMOS SRR; QUEIROZ MA. 2005. Recursos genéticos de abóbora no Nordeste brasileiro. In: LIMA MC (ed). Recursos genéticos de hortaliças: riquezas naturais. São Luís: Instituto Interamericano de Cooperação para a Agricultura. p. 99-116.

RAMOS SRR; QUEIRÓZ MA; CASALI VWD; CRUZ CD. 2009. Recursos genéticos de Cucurbita moschata: caracterização morfológica de populações locais coletadas no Nordeste brasileiro. Disponível em: http:// www.cpatsa.embrapa.br/catalogo/livrorg/ abobora.pdf/ Acessado em 12 de agosto de 2009.

ROMANO CM; RASEIRA MCB; NEITZKE RS; STUMPF ERT; BARBIERI RL. 2009. Caracterização de genótipos de pessegueiros ornamentais. Magistra 21: 268-276.

SANTOS-SEREJO JS; SOUZA EH; SOUZA FVD; SOARES TL; SILVA SO. 2007. Caracterização morfológica de bananeiras ornamentais. Magistra 19: 326-332.

SCACE PD. 2001. The floral artist's guide. Florence: Thomson Delmar Learning. 288p.

SILVA TE. 2012. Negócios de flores e plantas ornamentais avançam no Brasil. Disponível em: http://www.paginarural.com.br/ artigo/2089/negocios-de-flores-e-plantasornamentais-avancam-no-brasil/ Acessado em 13 de março de 2012.

SMITH E. 2006. Classic floral designs. New York: Sterling Publishing Co. 128p.

SOUZA FVD; CABRAL JRS; SOUZA EH; SANTOS ON; SEREJO JS; FERREIRA FR. 2007. Caracterização morfológica de abacaxizeiros ornamentais. Magistra 19: 319-325.

STONE HS; SIDEL JL. 1993. Sensory evaluation practices. San Diego: Academic Press. 308p.

TERRA SUL. 2010. Caracterização de abóbora ornamental. Disponível em: http://www. youtube.com/watch? $\mathrm{v}=\mathrm{qFCiUX}$ _zHb8/ Acessado em 21 de julho de 2010. 